\title{
Fabrication of Light Scattering Structure by Self-organization of a Polymer: Application to Light Out-coupling Enhancement in OLEDs
}

\author{
Satoru Ohisa, Naoya Takahashi, Yong-Jin Pu*, and Junji Kido* \\ Department of Organic Device Engineering, Research Center for Organic Electronics, \\ Yamagata University, 4-3-16 Jonan, Yonezawa, Yamagata 992-8510 Japan \\ pu@yz.yamagata-u.ac.jp; kid@yz.yamagata-u.ac.jp
}

\begin{abstract}
Light scattering structures for light out-coupling enhancement in organic light emitting devices (OLEDs) were fabricated by self-organization of poly[(9,9-di- $n$-octylfluorenyl2,7diyl)-alt-(benzo[2,1,3]-thiadiazol-4,8-diyl)] (F8BT). The F8BT film spin-coated from chloroform or THF solution showed smooth surface, while the film spin-coated from the mixture of chloroform/1,4-dioxane or THF/1,4-dioxane solution showed rough wavy surface. Fourier transformation of the waves in the rough F8BT films exhibited large components having the wavelength corresponding to near-infrared region. Orange-emitting OLEDs were fabricated on the rough F8BT films. Indium zinc oxide (IZO) and organic layers were deposited by either evaporation or spin-coating. The surface roughnesses of the evaporated organic layers were same as the surface roughness of the F8BT. On the other hand, the spin-coated organic layer reduced the roughness of the F8BT. Both in the evaporated and the spin-coated OLEDs, the external quantum efficiencies of OLEDs were increased by 1.2 times compared with those of the OLEDs without the F8BT, indicating that the F8BT served as light scattering structure to enhance light out coupling.
\end{abstract}

Keywords: OLED, light out-coupling, light scattering, self-organization

\section{Introduction}

Organic light-emitting devices (OLEDs) have the distinguishing features of light weight, flexibility, high power efficiency, and being a surface light source, etc. OLEDs have penetrated next generation lighting, and the further growth of this market is anticipated.[1-4] Further improvement of power efficiency is required to be used extensively. The most important technology to enhance the power efficiency is light out-coupling. Generally speaking, the light out-coupling efficiency in OLED without any out-coupling technology is only 20-30\%.[5-7] Therefore, extracting residual light in the device to air (air mode) is extremely important. The residual light is confined to organic layers, an anode (waveguide mode) and a substrate (substrate mode), because total reflection arises at the interfaces due to refractive indices mismatch. The residual light become reduced due to surface plasmon resonance with cathode metal (plasmon loss mode).

There are three kinds of out-coupling technology: surface plasmon loss reduction, internal out-coupling, and external out-coupling.[8-19] Internal out-coupling converts the waveguide mode to the substrate mode and the air mode. External out-coupling converts the substrate mode to the air mode. Recently development of the internal out-coupling technology have attracted attention.[9-14] Diffraction or scattering in the structure between the substrate and the anode is used as internal extraction structure (IES). For example, the structures are periodic structure like photonic crystal and light scattering layer that includes wavelength-scale particles.[9-14] Koo et al. fabricated the periodic UV resin structure using buckling structure mold.[12] That periodic 
structure significantly increased current efficiency compared with that without the periodic UV resin. However, the fabrication method is complicated. Easier fabrication method of out-coupling structure is preferred.

In this work, we fabricated the light scattering structure using self-organized poly[(9,9-di- $n$-octylfluorenyl-2,7-diyl)-alt-(benzo[2,1,3]-thiadiazol-4,8 -diyl)] (F8BT) by simple spin-coating method. F8BT solution dissolved in the mixture of good and poor solvents, and was spin-coated on glass substrates. 1,4-Dioxane as poor solvent caused aggregation of F8BT, and rough wavy F8BT films were obtained. Fourier transformation of the waves in the rough F8BT films exhibited large components in near-infrared region. This waved F8BT film was incorporated into OLED structures. The efficiencies of OLEDs were increased by 1.2 times compared with those of the OLEDs without the F8BT, indicating that the F8BT served as IES to enhance light out coupling.

\section{Experiment}

2.1 Internal extraction structure (IES) fabrication

The IES was fabricated by spin-coating using the mixture of good and poor solvents. F8BT was dissolved in chloroform/1,4-dioxane or THF/1,4dioxane mixture. THF and chloroform are good solvents for F8BT, and 1,4-dioxane is poor solvent for F8BT. Volume ratios of 1,4-dioxane in the mixed solvents were from 8 to $10 \%$. F8BT solutions were spin-coated on glass substrates. Then the films were annealed at $130^{\circ} \mathrm{C}$ in $\mathrm{N}_{2}$ purged glove box.

\subsection{OLED fabrication}

The OLEDs were fabricated by evaporation or solution method. All size of emission area was 2 $\mathrm{mm} \times 2 \mathrm{~mm}$. The structure of the evaporation processed OLEDs were [Indium zinc oxide (IZO) $(130 \mathrm{~nm}) /$ 1,4,5,8,9,11-hexaazatriphenylene hexa carbonitrile (HATCN) (30 nm)/ 1,1-bis $\{4-[N, N$ -di(p-tolyl)amino]phenyl $\}$ cyclohexane (TAPC) (50 $\mathrm{nm}) / \quad$ 4,4,4-tris $(N$-carbazolyl)triphenylamine (TCTA): $1 \mathrm{wt} \%$ bis(2-phenylquinoline) (2,2,6,6tetramethylheptane-3,5-dionate)iridium $\left(\mathrm{PQ}_{2} \operatorname{Ir}(\mathrm{dpm})\right)(10 \mathrm{~nm}) /$ 2-methyl-4,6-bis(3,5-di4-pyridylphenyl)pyrimidine (B4PYMPM) $(60 \mathrm{~nm}) /$ 8-quinolinolato lithium (Liq) $(1 \mathrm{~nm}) / \mathrm{Al}(100 \mathrm{~nm})]$. IZO anodes $(130 \mathrm{~nm})$ were sputtered on the IESs using facing targets sputtering system (FTS corporation NFTS-3S-AR). All organic layers and Al cathodes were evaporated under high vacuum.
The structure of the solution processed OLEDs were [IZO $(130 \mathrm{~nm}) /$ neutralized PEDOT:PSS (30 $\mathrm{nm}) /$ interlayer (IL) $(20 \mathrm{~nm}) /$ Blue emitting polymer: $\quad 10 \mathrm{wt} \% \quad \operatorname{tris}[2-(4-n$-hexylphenyl) quinoline]]iridium(III) $\quad \operatorname{Hex} \operatorname{Ir}(\mathrm{Phq})_{3} \quad(\mathrm{EML})(70$ $\mathrm{nm}) / \mathrm{Cs}_{2} \mathrm{CO}_{3} / \mathrm{Al}(100 \mathrm{~nm})$. All organic layers and $\mathrm{Cs}_{2} \mathrm{CO}_{3}$ electron injection layer were spin-coated in $\mathrm{N}_{2}$ purged glove box. $\mathrm{Al}$ cathodes were evaporated under high vacuum. Acidic PEDOT:PSS dissolved IES/IZO stack. Therefore PEDOT:PSS was neutralized with $\mathrm{NaOH}$ aqueous solution. For comparison, OLEDs without IESs were fabricated. In these devices, flat F8BT layers $(30 \mathrm{~nm})$ were inserted between the substrate and the anode instead of the IESs. F8BT solution dissolved in $p$-xylene was spin-coated. The flat F8BT film was obtained. The flat F8BT layer was clear yellow, not scattering light.

\subsection{Measurement}

Surface profiles were measured using AFM (Veeco Dimension icon). Scanning areas were 20 $\mu \mathrm{m} \times 20 \mu \mathrm{m}$. Surface profiles were Fourier transformed and power spectra were obtained. The current density-voltage characteristics and the luminance-voltage characteristics of the OLEDs were measured using a current source Keithley 2400 and a luminance meter Konica Minolta CS-200, respectively. EL spectra were measured using an optical multichannel analyzer Hamamatsu Photonics PMA-11. The angular dependences of luminance were measured using a current source Keithley 2400 and a spectral radiance meter Konica Minolta CS-2000.

\section{Results and discussion}

\subsection{Characterization of IESs}

Surface profiles of IESs made of F8BT were measured (Figure 1). Many micro-domains were observed. These films were whitish-yellow and hazy. F8BT films spin-coated using only chloroform was clear yellow. Boiling point of 1,4-dioxane $\left(101^{\circ} \mathrm{C}\right)$ is higher than those of chloroform $\left(61{ }^{\circ} \mathrm{C}\right)$ and THF $\left(66{ }^{\circ} \mathrm{C}\right)$. Therefore 1,4-dioxane dries slower than chloroform and THF, when the film is dried out, and causes aggregation of F8BT. Then F8BT forms the micro-domains. Figure 1(a) inset and 1(b) shows the Fourier transformation of the surface profiles of IESs and the power spectra, respectively. The similar results were obtained both in the IESs using chloroform/1,4-dioxane and THF/1,4-dioxane mixed solvents. Large components of the waves on the film surface were observed in the near-infrared 
a)
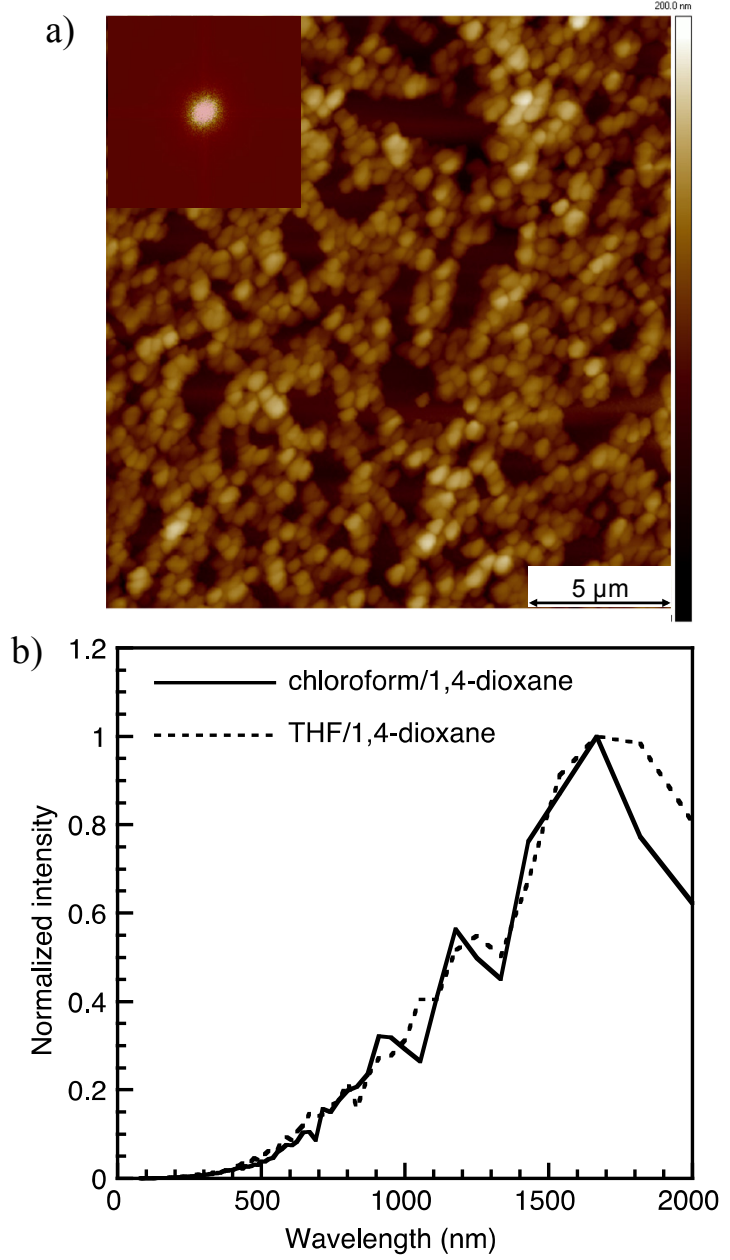

Figure 1. (a) 2-Dimension surface profiles of IES using chloroform/1,4-dioxane mixture. Inset: FFT images. (b) Power spectra of IESs using chloroform/1,4-dioxane and $\mathrm{THF} / 1,4$-dioxane mixtures.

region. The components in visible region were relatively small. It is usually assumed that the grating that has the periodicity of visible light wavelength works nicely for visible light out-coupling. However, according to the previous report, the components in near-infrared light region were important for visible light out-coupling.[12] Therefore the fabricated IESs in this work is expected to be advantageous for visible light out-coupling.

\subsection{Surface roughness of the stacked layers}

The surface roughnesse of the stacked layer on the IES were investigated. Surface roughness of anode may influence the leakage currents of OLEDs. Also interface roughness between the organic layer and cathode metal may influence the surface plasmon loss mode. For simplicity, the structure of [Glass/ IES/ IZO (130 nm)/ HATCN (30 nm) $/ \quad N, N^{\prime}$-Di(1-naphthyl)- $N, N^{\prime}$-diphenyl benzidine $(\alpha-\mathrm{NPD})(100 \mathrm{~nm})]$ was used as an a)

$\mathrm{Ra}(\mathrm{nm})$

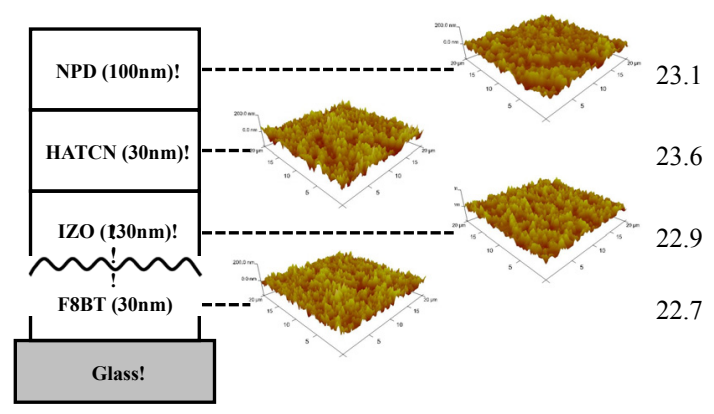

b)

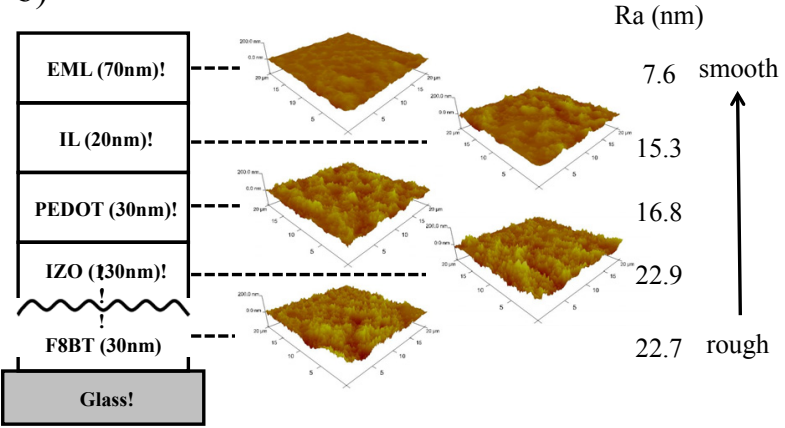

Figure 2. Surface roughnesses of the each stacked layers: (a) evaporated and (b) spin-coated.

evaporated layer stack. Figure 2 shows the surface roughnesses of the each stacked layers. The surface roughnesses of anode and evaporated organic layers were the same as that of the IES. The surface roughness of the evaporated layers reflected the surface roughness of the IES. On the other hand, the surface roughnesses of the spin-coated organic layers were lower than that of the IES. The solution process reduced the roughness of the underlayers derived from the IES.

\subsection{Out-coupling effects in OLEDs}

OLEDs with the IESs were evaluated to verify out-coupling effects. Figure 3 and Table 1 show the characteristics of the OLEDs. The IES in the evaporated OLED was fabricated using $\mathrm{THF} / 1,4$-dioxane and that in the spin-coated OLED was fabricated using chloroform/1,4dioxane. Fourier transformations of the IESs were almost same. Therefore, we assume that the each results can be compared each other. In the evaporated OLED, EL spectra had the peak around $600 \mathrm{~nm}$. The current density of the OLED with the IES was slightly larger than that of the OLED without the IES. It is assumed that concentration of electric field due to surface roughness caused the increment of the current density. External quantum efficiency of the OLED with the IES increased compared with that of the OLED without the IES. The increment was $20 \%$ taking account of the 
a)

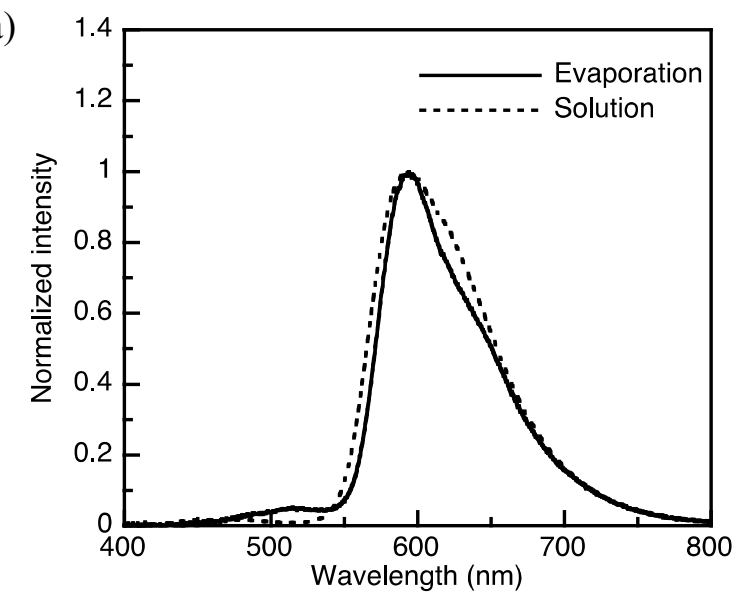

c)

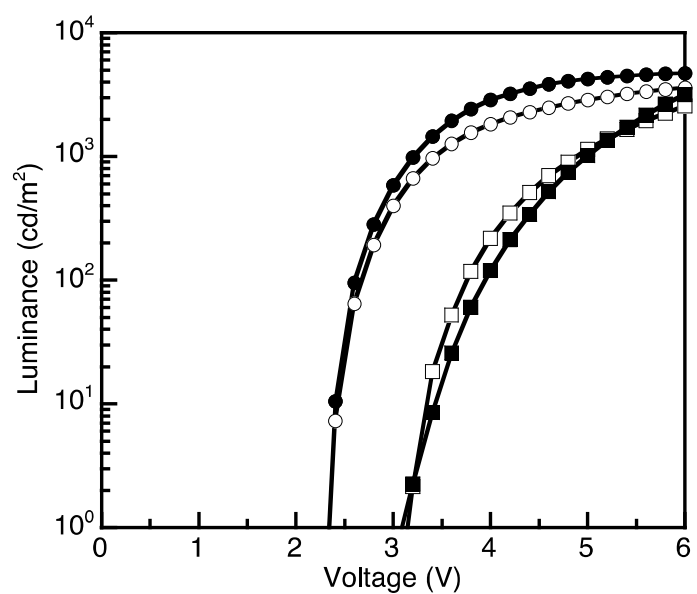

b)

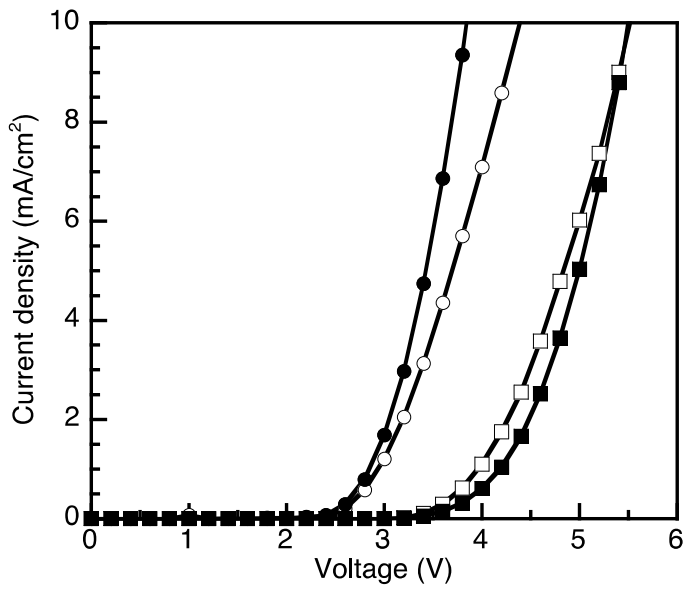

d)

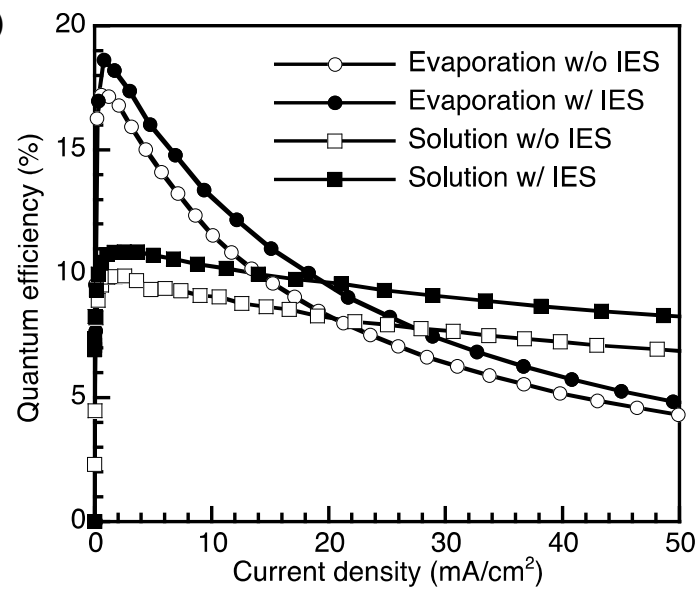

Figure 3. (a) EL spectra, (b) current density-voltage characteristics, (c) luminance-voltage characteristics and (d) quantum efficiency-current density characteristics of OLEDs. Quantum efficiencies were calculated based on Lambertian assumption.

Table 1. OLED characteristics at $10 \mathrm{~mA} / \mathrm{cm}^{2}$ corrected with angular dependence correction

\begin{tabular}{cccccc}
\hline & $\begin{array}{c}\text { Voltage } \\
(\mathrm{V})\end{array}$ & $\begin{array}{c}\text { Luminance } \\
\left(\mathrm{cd} / \mathrm{m}^{2}\right)\end{array}$ & $\begin{array}{c}\text { Quantum efficiency } \\
(\%)\end{array}$ & $\begin{array}{c}\text { Power efficiency } \\
(\mathrm{lm} / \mathrm{W})\end{array}$ & Lambertian factor \\
\hline $\begin{array}{c}\text { Evaporation } \\
\text { w/o IES }\end{array}$ & 4.4 & 2278 & 10.9 & 15.3 & 0.94 \\
$\begin{array}{c}\text { Evaporation } \\
\text { w/ IES }\end{array}$ & 3.8 & 2530 & 13.2 & 21.0 & 1.01 \\
$\begin{array}{c}\text { Spin-coating } \\
\text { w/o IES }\end{array}$ & 5.5 & 1837 & 9.0 & 10.4 & 0.99 \\
$\begin{array}{c}\text { Spin-coating } \\
\text { w/ IES }\end{array}$ & 5.5 & 1948 & 10.9 & 11.8 & 1.06 \\
\hline
\end{tabular}

angular dependence correction. In the spin-coated OLED, EL spectra was similar with the evaporated OLED. Therefore, comparison of light out-coupling efficiency between the evaporated OLED and the spin-coated OLED was possible. The current density of the OLED with the IES was almost similar with the OLED without the IES in contrast to the evaporated OLED. The planarized effect by solution process may have suppressed the leakage current of the OLED with the IES. External quantum efficiency of the OLED with the IES also increased compared with that of the
OLED without the IES. The increment taken account of the angular dependence correction was $20 \%$ and that was the same as that of the evaporated OLED. The IES increased the light out-coupling efficiencies. The difference of the interface roughnesses between the organic layer and cathode metal didn't influence the light out-coupling efficiencies. Surface plasmon loss may usually be reduced by rough interface. However, these surface roughnesses were small, compared with visible light wavelength. The degrees of the surface roughnesses may be 
insufficiently small for reduction the surface plasmon loss. In this work, all size of emission area is $4 \mathrm{~mm}^{2}$, and external out coupling films were not attached. If large emission area OLED with IES and light out-coupling film was fabricated, the increment of the light out-coupling efficiency may be larger than that with only light out-coupling film by the synergy effect.

\section{Conclusion}

We fabricated the IESs made of F8BT by simple spin-coating method. We fabricated OLEDs using the IESs to enhance light out-coupling. The IESs increased the external quantum efficiencies of OLEDs by 1.2 times compared with those of OLEDs without the IESs. These results didn't depend on the fabrication methods, evaporation and spin-coating, of OLEDs. Interface roughness between organic layer and cathode metal didn't influence the light out-coupling efficiency. The internal out-coupling technology will be key technology for the development of high power efficiency device.

\section{Acknowledgement}

We would like to thank the "Strategic Promotion of Innovative R\&D Program" and the "Japan Regional Innovation Strategy Program by Excellence" of Japan Science and Technology Agency (JST) for financial support.

\section{References}

[1] J. Kido, M. Kimura, K. Nagai, Science, 267 (1995) 1332.

[2] H. Sasabe, J. Kido, J. Mater. Chem. C., 1 (2013) 1699.

[3] T. Komoda, K. Yamae, V. Kittichungchit, H. Tsuji, N. Ide, SID 12 Digest , (2012) 610.

[4] K. Sugi, T. Ono, D. Kato, T. Yonehara, T.
Sawabe, S. Enomoto, I. Amemiya, SID 2012 Digest, (2012) 1548.

[5] A. Chutinan, K. Ishihara, T. Asano, M. Fujita, S. Noda, Org. Electron., 6 (2005) 3.

[6] N.C. Greenham, R.H. Friend, D.D.C. Bradley, Adv. Mater., 6 (1994) 491.

[7] A. Werner, C. Rothe, U. Denker, D. Pavicic, M. Hofmann, S. Mladenovski, K. Neyts, SID 08 Digest, (2008) 522.

[8] T. W. Canzler, S. Murano, D. Pavicic, O. Fadhel, C. Rothe, A. Haldi, M. Hofmann, Q. Huang, SID 11 Digest, (2011) 975.

[9] Y-S Tyan, Y.Q. Rao, J-S. Wang, R. Kesel, T.R. Cushman, W.J.Begley, SID 08 Digest, (2008) 933.

[10] H-W. Cheng, K-C. Tien, M-H. Hsu, Y-H. Huang, C-C. W, SID 10 Digest, (2010) 50.

[11] J. Choi, T-W. Koh, S. Lee, S. Yoo, Appl. Phys. Lett., 100 (2012) 233303.

[12] W. H. Koo, S. M. Jeong, F. Araoka, K. Ishikawa, S. Nishimura, T. Toyooka, H. Takezoe, Nat. photonics, 4 (2010) 222.

[13] Y. Bai, J. Feng, Y.-F. Liu, J.-F. Song, J. Simonen, Y. Jin, Q.-D. Chen, J. Zi, H.-B. Sun, Org. Electron., 12 (2011) 1927.

[14] Y.R. Do, Y.-C. Kim, Y.-W. Song, Y.-H. Lee, $J$. Appl. Phys., 96 (2004) 7629.

[15] F. Galeotti, W. Mróz, G. Scavia, C. Botta, Org. Electron., 14 (2013) 212.

[16] J. Zhou, N. Ai, L. Wang, H. Zheng, C. Luo, Z. Jiang, S. Yu, Y. Cao, J. Wang, Org. Electron., 12 (2011) 648.

[17] C. F. Liu, C. T. Pan, Y. C. Chen, Z. H. Liu, C.J. Wu, Opt. Commun., 291 (2013) 349.

[18] S. Moller, S.R. Forrest, J. Appl. Phys., 91 (2002) 3324.

[19] S. Reineke, F. Lindner, G. Schwartz, N. Seidler, K. Walzer, B. Lussem, K. Leo, Nature, 459 (2009) 234. 